\title{
ADVANCED ICT TOOLS FOR IMPLEMENTATION OF THE COMPLEX CALCULATIVE STUDY
}

\author{
${ }^{1 *}$ Dr. Capt. K. Sujatha,${ }^{2}$ N. Devi Priya, ${ }^{3}$ Dr. K. S.V. K. S. Madhavi Rani,${ }^{4}$ Dr.A.Nirmala Jyothsna \\ ${ }^{5}$ Dr. Srivastava. Pratima Kumari , ${ }^{6}$ Dr.V.Nagalakshmi \\ 1. Professor \& Head, Department of Mathematics, St. Joseph's College for Women (A), Visakhapatnam, A.P, India \\ 2. Lecturer, Department of Computer Science, JMJ College for Women (A), Tenali, A.P, India \\ 3. Associate Professor, Department of Zoology, Ch.S.D.St.Theresa's College for Women (A),Eluru, A.P, India \\ 4. Associate Professor \& Head, Department of Physics \& Electronics, Ch.S.D.St.Theresa's College for Women (A) \\ Eluru, A.P, India \\ 5. Associate Professor, Department of Zoology, Ch.S.D.St.Theresa's College for Women (A) Eluru, A.P, India \\ 6. Associate Professor, Department of Chemistry, Ch.S.D.St.Theresa's College for Women (A) Eluru, A.P, India
}

\begin{abstract}
India being a nation of Mathematicians like Srinivasa Ramanujam, Aryabhata, Shakuntala Devi, and so forth is constantly celebrated for worldwide numerical commitments throughout time. In the current circumstance, math is a subject that most understudies attempt to dodge because of its extensive counts and complex definitions. Numerous nations around the globe have done several turns of events and developments for mathematical calculations in the field of Chemistry, Physics, Electronics, Computer Science, and so forth with the assistance of cutting-edge Information Communication Technology (ICT) apparatuses. Indian mathematical subsystems also need to evolve and upgrade to meet the global professional competition from the grassroots level. There is a genuine need to join ICT instruments for mathematics in school and college education to have a superior agreement. The joining of ICT instruments can change the course of calculative study to calculative upgrade which further prompts higher concept understanding and perspective development. This paper discusses the new improvement in the field of advanced calculation and how it is limiting the weight on understudies. As per Prytherch (2000), "ICTs are networks that provide new opportunities for teaching, learning, and training through the delivery of digital content. "Integration technology in education means giving experiential learning to the students. Software tools for calculation are utilized in the study hall for improving intellectual capacity and abilities in students especially to diminish computation stress among them.
\end{abstract}

\section{Introduction}

In the era of globalization, the education society is going through many opportunities and challenges. ICT integration in education was a role changer for the teaching-learning process but implementing it was a challenge as well. The trend of the classroom has been shifted from teachercantered to student-cantered and the teacher became a guide, facilitator, blackboards turned into whiteboard, SMARTBOARD, Artificial intelligence \& Virtual reality tools being used for imparting knowledge.

Integrating ICT in curriculum encouraging the use of applications for Teaching Learning. (NCTM, 2000) (Is, 1998) National Council of Teachers of Mathematics suggested that using technology is part of teaching strategies. NCTM states that" It is important for teachers and students should have access to technologies that support and advance mathematical sense-making, reasoning, problem-solving, and communication. Effective teachers optimize the potential of technology to develop students' understanding, stimulate their interest, and increase their proficiency in mathematics. When teachers use technology strategically, they can provide greater access to mathematics for all students" (NCTM, 2000).[1]

\section{Literature Survey}


(Kilicman et al., 2010) Done a study on, "Teaching and Learning Mathematics with tool". He had done the review on the recent Italian tools used in Mathematics'teaching. He reviewed the studies related to the software like: 'The DGE: Dynamic Geometry Software, The CAS: Computer Algebra Systems, Spreadsheet for mathematic knowledge. He concluded his study by saying that only tools feature is not the parameter to decide the integration of technology in the classroom also features like classroom activity, interaction among teachers and students \& between the students are also important.

(Barry, 2017) Have entitled his study "Alleviating Math Anxiety through the Integration of Technology in Elementary School" This study discusses the strategies, outcome, and challenge in integrating technology in Mathematics teaching on primary school students. This study aims to answer questions related to factors influencing technologyintegrated teaching strategies and student outcome and engagement. As a sample two elementary school was taken and data was collected through a semi-structured questionnaire. The research concluded his study by saying teacher knowledge and belief toward technology.

(Das, 2019) named his study " Role of ICT for Better Mathematics Teaching" Study aim to explore the aspect of technology integration in mathematics teaching. The researcher has done a document-based analytical study for drawing the conclusion. He believed the role of mathematics is not limited to the academic domain only. He discusses the integration of ICT in Mathematics at the teacher training level. This study mentioned the drawbacks as poor infrastructure, teacher focus on PowerPoint Presentation creativity rather than content knowledge, Lack of technical skills in teachers.

(Sevari, 2018) Entitled his study "The effectiveness of mathematics software aided learning tool with performance assessment on student independence and student learning outcomes" done to verify the effect of mathematical software on performance of students. This was an experimental study done on the Mathematics Education Department of FMIPA Undiksha, 49 integral calculus students were a sample for this study. Result of this research shows those student performances were higher who were using mathematics software-assisted device in comparison to a conventional learning tool.

\section{ICT Tools for Teaching and Learning Mathematics}

Mathematics tools help students in concept building to perform calculation-related problems, which makes mathematics easier \& understandable.

\section{Maple}

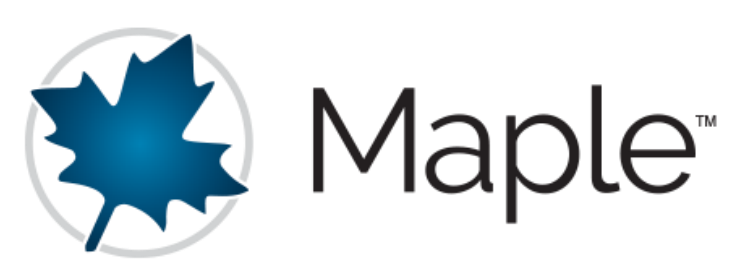

Figure.1 Logo of Maple

The tool is used for symbolic and numeric calculation data analysis, visualization in Mathematics. This serves only in $2 \mathrm{~d}$ processing. This tool open source and used for mathematics and engineering has a mathematics library as well. It is particularly useful for illustrating interval algorithms in the field of validating computing. Maple software is generally used for college students. It contains almost 45 tutorial which is used for teaching-leaning process for undergraduate students. This tool contains mathematics concepts related to, calculus, algebra, complex variable, vector. this tool helps in understanding the steps of calculation while solving the problem.Maple2020 has updated the software by including some new features and also upgraded for solving the problems, document creation, interactive problem-solving.This 
software needless programming in comparison to other software.

\section{Output}

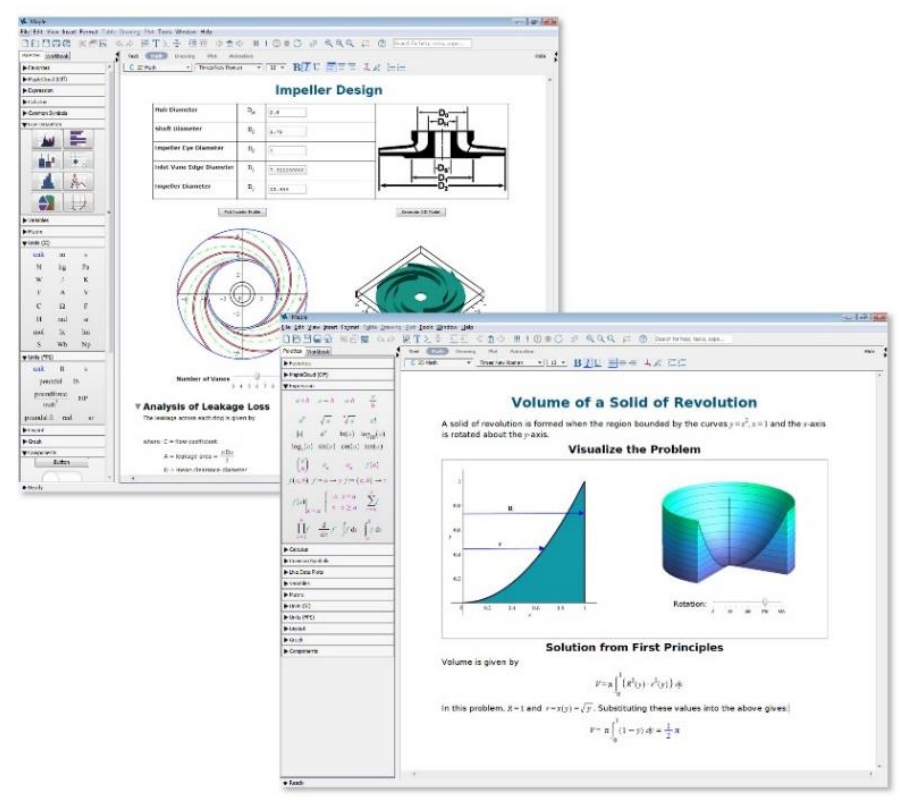

\section{Mathematica}

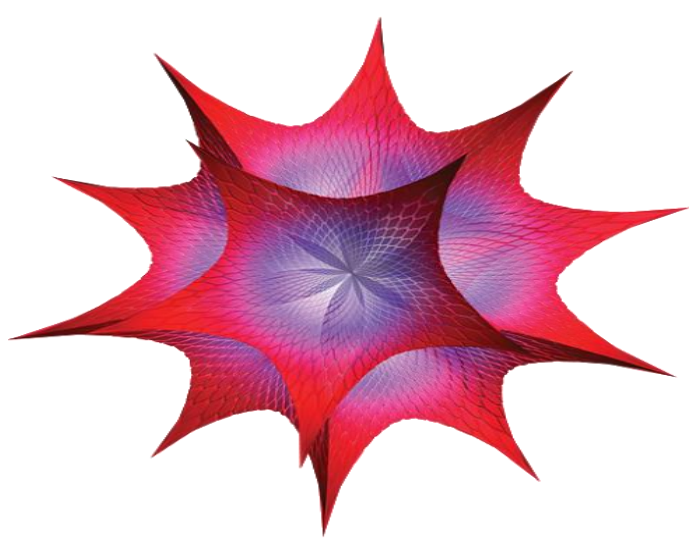

Figure.2 Logo of Mathematica

This software is constructed to solve numerical and symbolic problems in mathematics. This tool is generally used in the field of engineering, Science, computing fields. It provides excellent visualization in $2 \mathrm{D}$ and $3 \mathrm{D}$. Mathematica is developed by Wolfram Research of Champaign, and he grants free access and accounts on the latest version of the software.
This tool can be used for self-learning with the help of tutorials.

\section{Output}

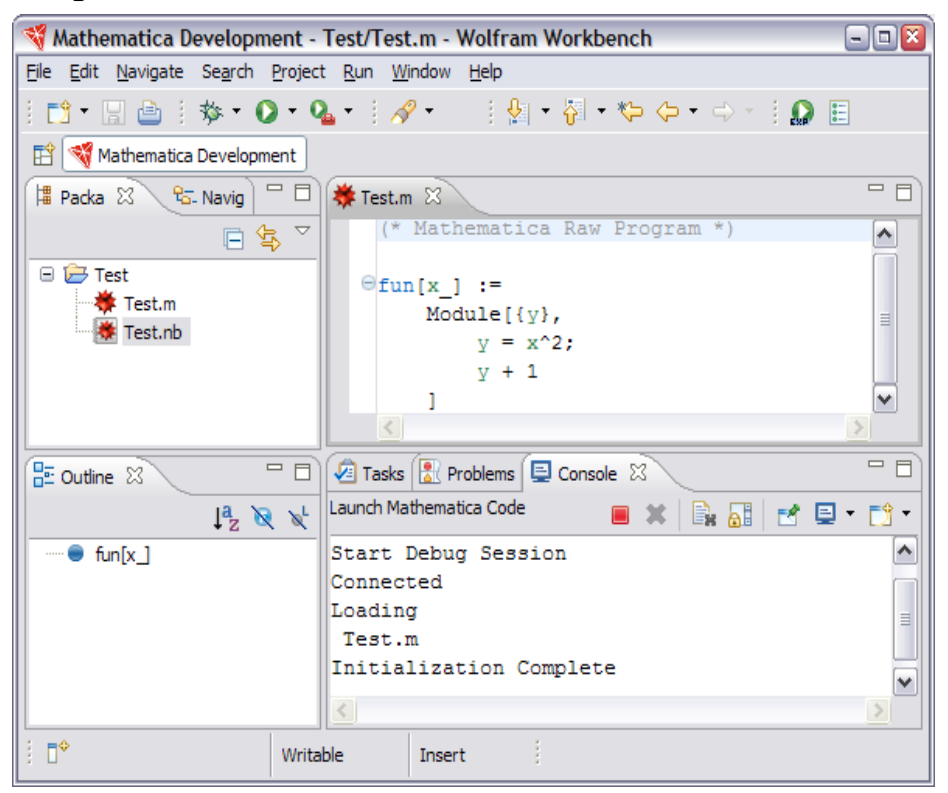

\section{MatLab}

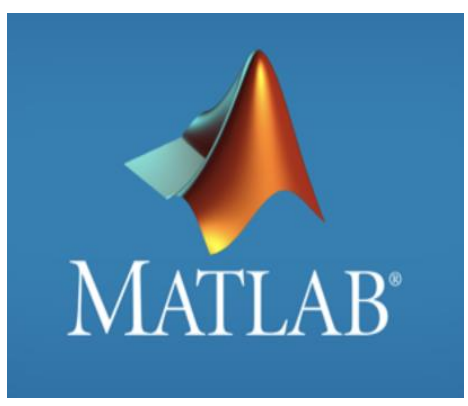

Figure.3 Logo of MatLab

It is an interactive system which helps you in solving complex computing problem, particularly with matrix and vector difficulties. Toolboxes of MatLab help you to learn and employ technology. This software can be used to accomplish multiple tasks related to Math and computation, Algorithm development, Modeling, simulation, and prototyping Data analysis, exploration, and visualization Scientific and engineering graphics Application development, including Graphical User Interface building. This software is not accessible for free. 
Output

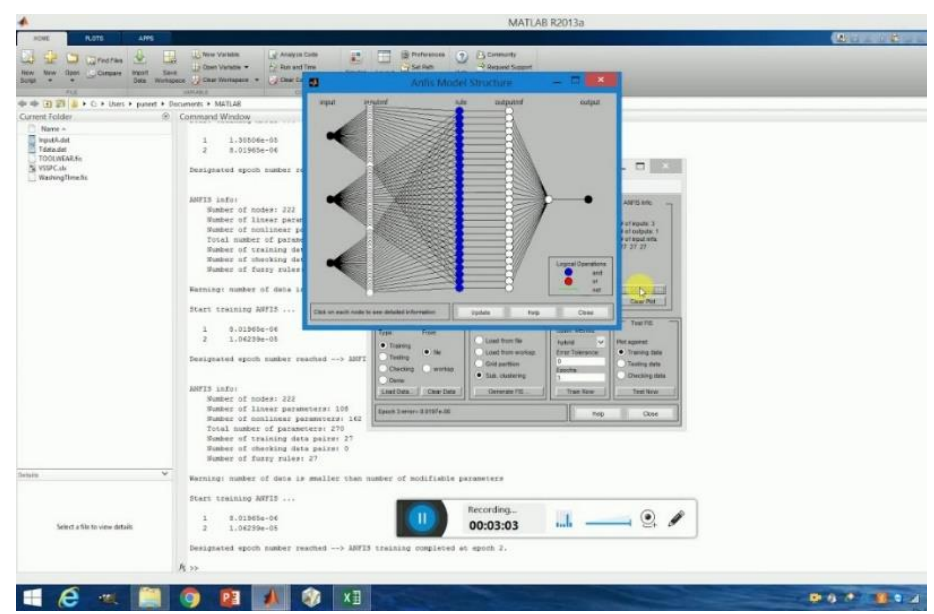

SciLab

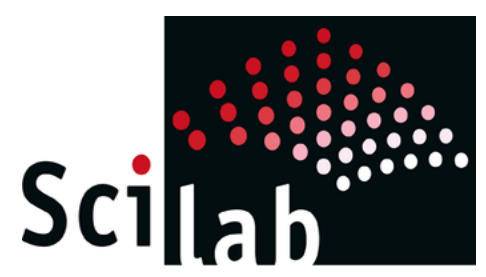

Figure.4 Logo of Scilab

This is free and open software used for complex calculations. It uses scientific computing techniques. Scilab has a separate module for image processing. This software is most easy to use and provides various techniques for numerical calculation. A user can develop their module and execute their specific problem. Previously Scilab focused only on linear algebra but at present, it is covering many topics related to scientific computing. It provides a set of plotting functions and graphic features. The Xcos setting provides a hybrid dynamic systems modeler and simulator.
Output

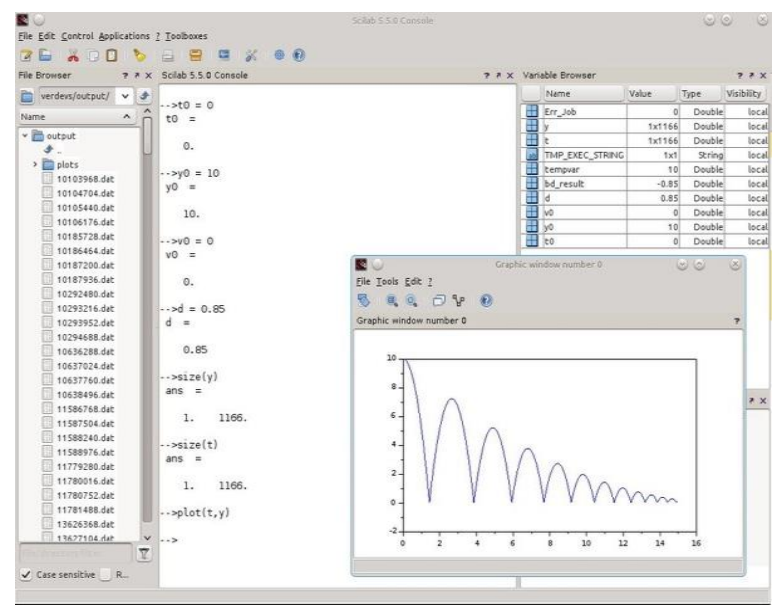

\section{GeoGebra}

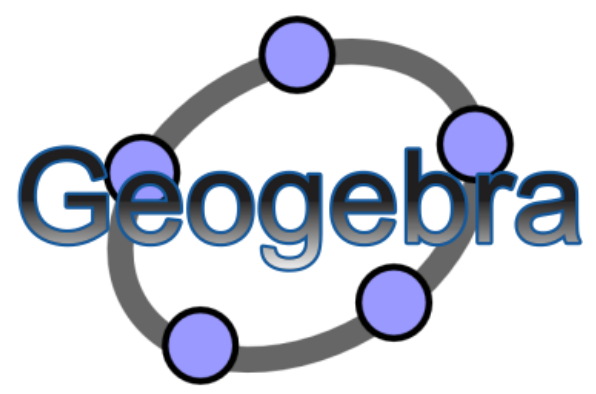

Figure.5 Logo of GeoGebra

GeoGebra is a tool that can be used for middle school to college levels students for Mathematics education. This tool contains all sections of mathematic. One can perform all the calculations related to geometry, algebra, spreadsheets, graphing, statistics, and calculus in this tool. It is free software where a student can explore experiments with objects and parameters for concept building in the mathematical curriculum. GeoGebra provides bi-directional representations of geometry and algebra. 
Output

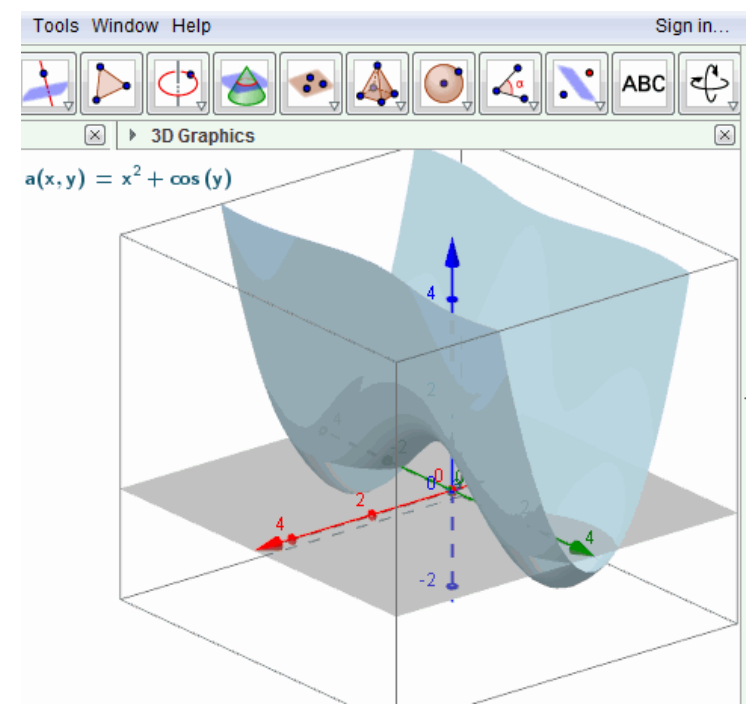

Winplot

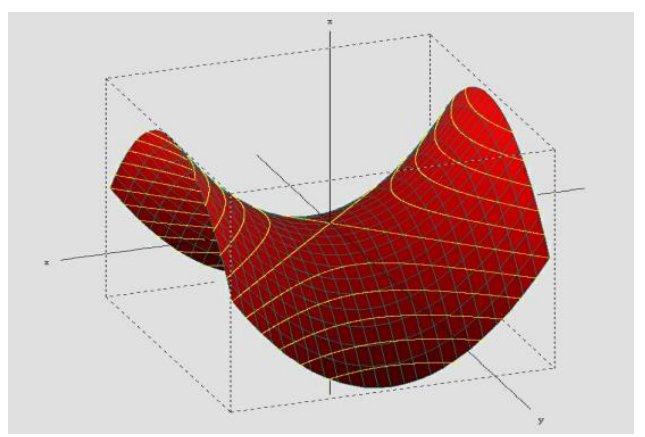

Figure.6 Logo of Winplot

Winplot is a plotting utility for Microsoft Windows, It can draw and animate mathematical curves and surfaces presented in a variety of formats. learners can drag and move their objects without redoing the drawing. So that learners have more time to think about the concept building rather than spending time restructure the drawing. Winplot can perform many procedures on functions like generating graphs of crosssectional solid, detect trajectory on a slope, calculating line and surface integral.

\section{Output}

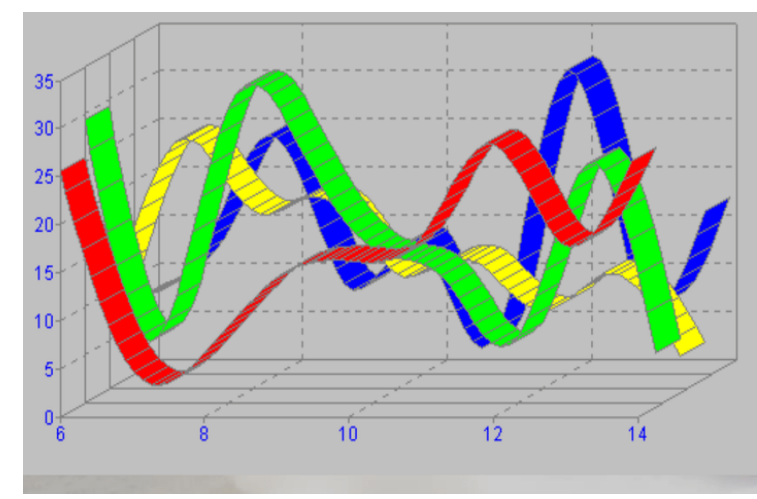

\section{Real-time Programming and Examples}

\section{Example 1 - Manual calculation vs. CAS calculation}

Find the determinant of a matrix $A=\left[\begin{array}{lllll}7 & 6 & 9 & 5 & 6 \\ 3 & 8 & 7 & 5 & 7 \\ 5 & 4 & 6 & 8 & 7 \\ 1 & 2 & 3 & 8 & 7 \\ 7 & 5 & 3 & 1 & 5\end{array}\right]$.

This will take huge time manually and if we calculated the answer still we need to verify it.

\section{Software Used - Scilab}

Just 2 lines of code can bring the answer in few seconds.

-->A = [76956; $38757 ; 54687 ; 12387 ; 75315]$

--> $\operatorname{det}(\mathrm{A})$ 


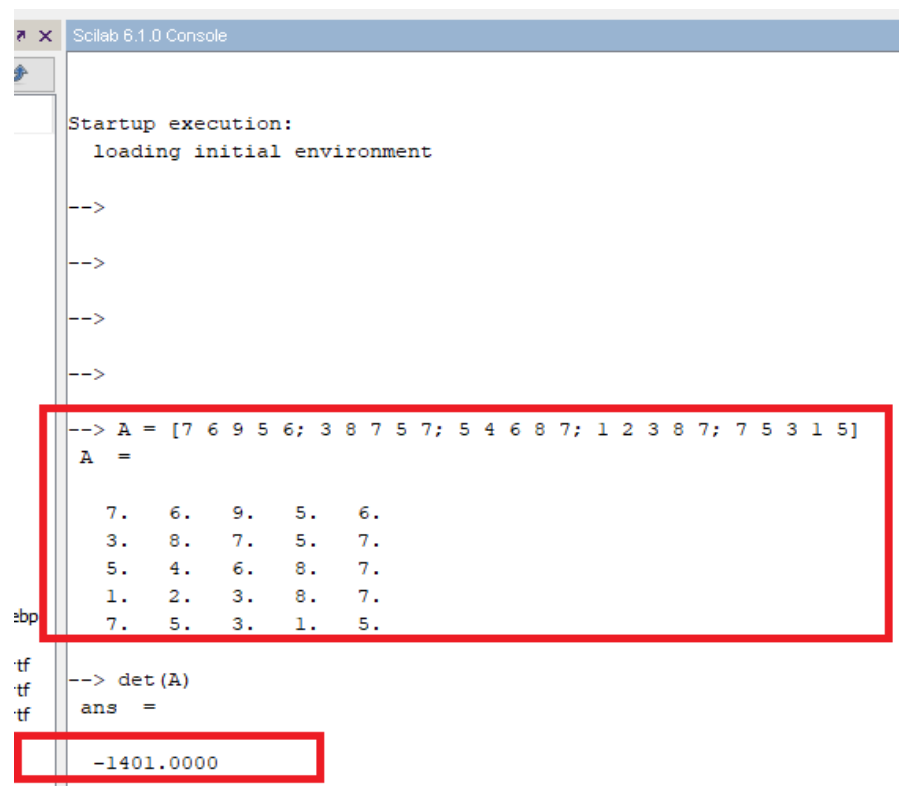

Figure.7 Scilab

\section{Example 2 - SIN 3D Plot}

Plot 3D Plot of SIN function.

It's practically impossible to plot SIN 3D plot from all direction and rotate it on paper manually. CAS software can do it effortlessly.

\section{Software Used - MATLAB}

Just 8 lines of code can bring the answer in few seconds.

\section{Program}

$\mathrm{a}=0: 0.01: 1$;

$\mathrm{b}=\sin (2 * \mathrm{pi} * \mathrm{a})$

$\mathrm{c}=\mathrm{b}^{\prime} * \mathrm{~b}$;

$\operatorname{surf}(\mathrm{c})$

xlabel('X AXIS')

ylabel('Y AXIS')

zlabel('Z AXIS')

title('SIN 3D PLOT')

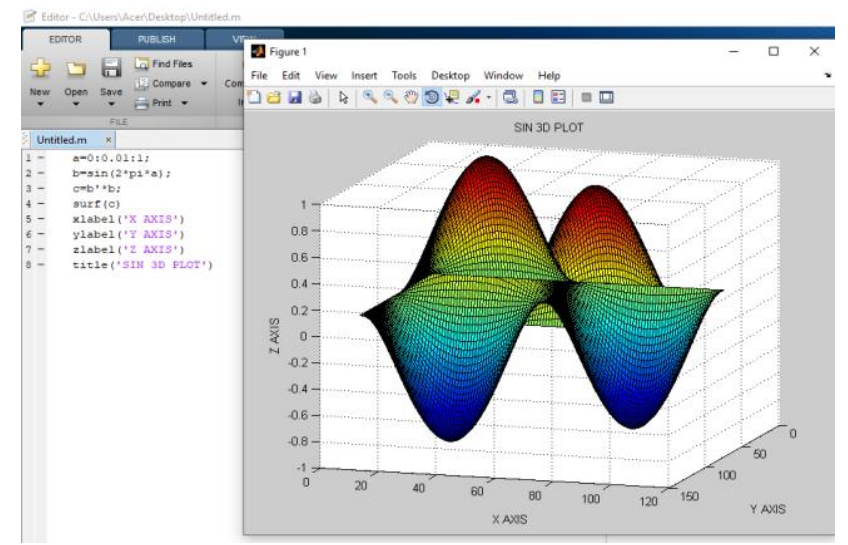

Figure.8 MatLab

Example 3 - Find the solution to the following set of linear equations

$$
\begin{aligned}
& 2 x-3 y+4 z=5 \\
& y+4 z+x=10
\end{aligned}
$$

$-2 z+3 x+4 y=0$

\section{Software Used - MATLAB}

Just 5 lines of code can bring the answer in few seconds.

\section{Program}

$$
\begin{aligned}
& \text { syms x y z; } \\
& \text { eq1 }=\text { ' } 2 * x-3 * y+4 * z=5 ' \\
& \text { eq2 }=\text { ' } y+4 * z+x=10 ' \\
& \text { eq3 }={ }^{\prime}-2 * z+3 * x+4 * y=0 \text { ' } \\
& {[\mathrm{x}, \mathrm{y}, \mathrm{z}]=\text { solve }(\text { eq1 }, \text { eq2 }, \text { eq } 3, \mathrm{x}, \mathrm{y}, \mathrm{z})}
\end{aligned}
$$

\footnotetext{
Command Window

(i) New to MATLAB? Watch this Video see Examples, or read Getting Started.

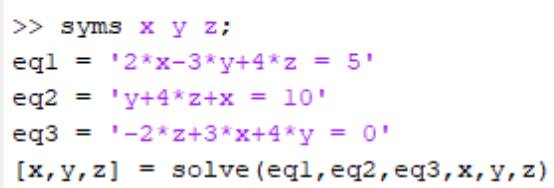




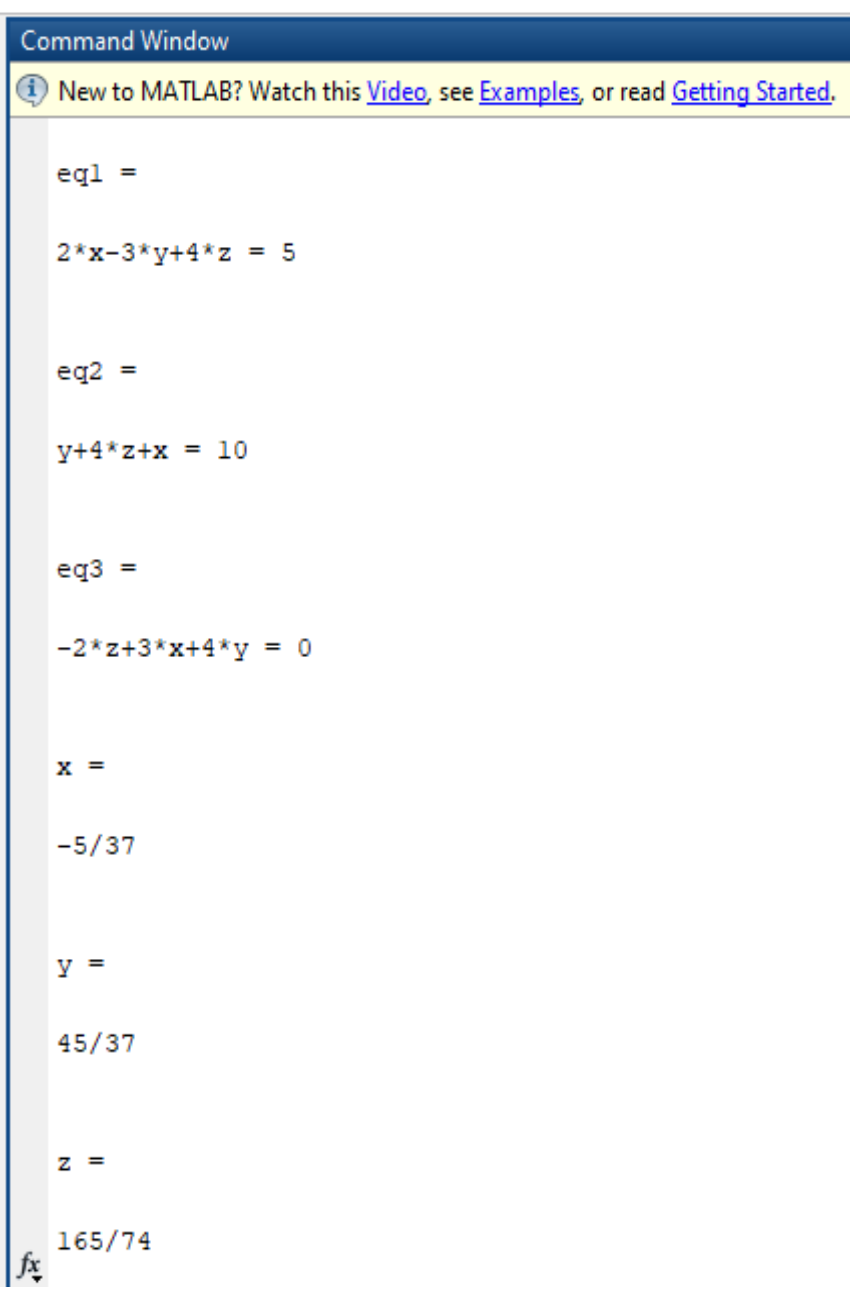

Example 4 - Find the solution by plotting these two equations and looking at their intersections.

$\exp 1=$ 'y $-2 * \exp (\mathrm{x}){ }^{\prime}$

$\exp 2={ }^{\prime} y-3+x^{\wedge} 2^{\prime}$

\section{Software Used - MATLAB}

Just 7 lines of code can bring the answer in few seconds.

\section{Program}

$\exp 1={ }^{\prime} \mathrm{y}-2 * \exp (\mathrm{x})^{\prime}$

$\exp 2={ }^{\prime} \mathrm{y}-3+\mathrm{x}^{\wedge} 2^{\prime}$

ezplot(exp1)

hold on

ezplot(exp2)

hold off

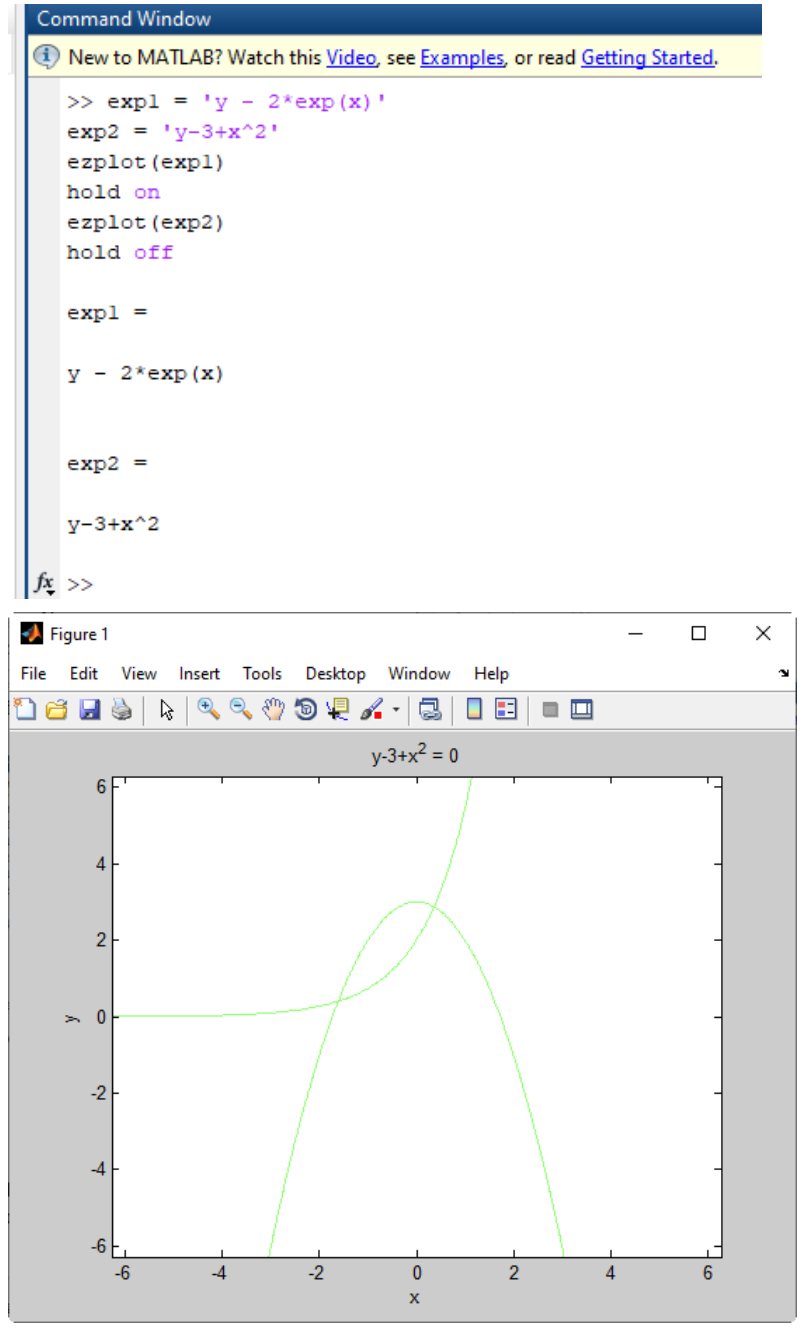

\section{Significance}

- Solve \& explain math problems easily and perfectly

- Solve any complex problems related to Mathematics from any kind of complex

- Create an interactive \& stress-free environment for learning.

- Make learning experiential.

- Enhance student cognitive skills of students.

- Reduce fear and anxiety of students from the mathematics curriculum.

\section{Conclusion}

In traditional teaching-learning, mathematics calculations were taking longer time taking process. After all the time when the calculations give you the wrong output, it 
demotivates the students. The concept of mathematics (formulas/theorem) was not easy to recall. All these reasons were creating fear in student's minds for mathematics. Integrating Technology-enhanced learning in school has created a hassle-free environment for students. The implementation of these Computer Aided Software can ease up the mathematical calculations for the staffs and students from departments like Physics, Chemistry, Mathematics, Computer Science, Zoology, electronics and engineering domains as well.

\section{REFERENCES}

1. Strategic Use of Technology in Teaching and Learning Mathematics - National Council of Teachers of Mathematics. (n.d.). Retrieved February 26, 2021, from https://www.nctm.org/Standards-and-Positions/PositionStatements/Strategic-Use-of-Technology-in-Teachingand-Learning-Mathematics/(International,n.d.)

International, S. (n.d.). Effects of Technology on Classrooms and Students.

2. Barry, A. (2017). Alleviating Math Anxiety through the Integration of Teacher Beliefs in Senior School. Journal Basic of Education, 3(April), 335-342.
3. Das, K. (2019). Role of ICT for better Mathematics Teaching. Shanlax International Journal of Education, 7(4), 19-28. https://doi.org/10.34293/education.v7i4.641

4. Is, W. (1998). Pssm. Journal of Equine Veterinary Science, 18(11), 719. https://doi.org/10.1016/s0737$\underline{0806(98) 80482-6}$

5. Kilicman, A., Hassan, M. A., \& Husain, S. K. S. (2010). Teaching and learning using mathematics software "the new challenge." Procedia - Social and Behavioral Sciences, 8, 613-619. https://doi.org/10.1016/j.sbspro.2010.12.085

6. Sevari, K. (2018). The Effectiveness of Math Educational Software on Creativity and Academic Achievement. Psychology and Behavioral Science International Journal, $8(4)$. https://doi.org/10.19080/pbsij.2018.08.555741

7. (Campbell et al., 2010)Campbell, S. L., Chancelier, J.-P., Nikoukhah, R., Campbell, S. L., Chancelier, J.-P., \& Nikoukhah, R. (2010). Introduction to Scilab. Modeling and Simulation in Scilab/Scicos with ScicosLab 4.4, 971. https://doi.org/10.1007/978-1-4419-5527-2_2 